BULLETIN Bulletin hispanique

HispaniQuE Université Michel de Montaigne Bordeaux

$116-2 \mid 2014$

Référentialité/autoréférentialité dans le roman espagnol contemporain : bilan et perspectives

\title{
Gerardo Diego y Juan Larrea
}

Primeras cartas (1916)

José Luis Bernal Salgado y Juan Manuel Díaz de Guereñu

\section{(2) OpenEdition}

\section{Journals}

\section{Edición electrónica}

URL: http://journals.openedition.org/bulletinhispanique/3656

DOI: 10.4000/bulletinhispanique.3656

ISBN: 979-10-300-0156-3

ISSN: 1775-3821

Editor

Presses universitaires de Bordeaux

Edición impresa

Fecha de publicación: 1 diciembre 2014

Paginación: 899-917

ISBN: 978-2-86781-963-6

ISSN: 0007-4640

Referencia electrónica

José Luis Bernal Salgado y Juan Manuel Díaz de Guereñu, «Gerardo Diego y Juan Larrea », Bulletin hispanique [En línea], 116-2 | 2014, Publicado el 01 diciembre 2017, consultado el 01 mayo 2019. URL : http://journals.openedition.org/bulletinhispanique/3656; DOI : 10.4000/bulletinhispanique.3656 


\title{
DOCUMENTS
}

\section{Gerardo Diego y Juan Larrea: Primeras cartas (1916)}

\author{
José Luis Bernal Salgado \\ Universidad de Extremadura \\ Juan Manuel Díaz de Guereñu \\ Universidad de Deusto
}

En octobre 1916, Gerardo Diego et Juan Larrea, récemment diplômés de l'Université de Deusto, entament une correspondance qui se poursuit jusqu'à la mort de Larrea en 1980. Les premières lettres que les deux jeunes amis échangent cette année-là témoignent d'inquiétudes littéraires et d'un apprentissage de la poésie partagés.

Mots-clés : Gerardo Diego, Juan Larrea, lettres, poésie, apprentissage.

En octubre de 1916, Gerardo Diego y Juan Larrea, recién licenciados en Letras por la Universidad de Deusto, iniciaron una correspondencia que siguió hasta la muerte de Larrea en 1980. Las primeras cartas que intercambiaron los dos amigos en ese año son buena muestra de las inquietudes literarias y del aprendizaje de la poesía que ambos jóvenes compartieron.

Palabras clave: Gerardo Diego, Juan Larrea, cartas, poesía, aprendizaje.

In October 1916, Gerardo Diego and Juan Larrea, who had then just graduated from the University of Deusto, began a correspondence that went on until Larrea's death in 1980. The first letters between the two friends in that year 1916 are good examples of the literary interests and of the process of learning poetry writing shared by both young men.

Keywords: Gerardo Diego, Juan Larrea, letters, poetry, learning.

T a correspondencia entre Gerardo Diego y Juan Larrea constituye un L conjunto de documentos excepcional entre los que nos han legado los poetas de su tiempo. Lo es por su abundancia, por su extensión temporal y por 
la densidad de su contenido en lo poético y en lo personal. La mayoría de las cartas que escribió Larrea, doscientas dieciséis, se han publicado ya, pero sólo unas pocas de las que Diego le envió, siete, han visto la luz'. Es una lamentable consecuencia más de la embarullada peripecia del archivo personal de Juan Larrea, que, pese a que el proyecto de publicar el epistolario íntegro cuenta con la aquiescencia de los herederos de ambos poetas, ha impedido largo tiempo la consulta de los originales de las cartas de Diego en él depositadas.

Tras tan larga dilación, llega al fin la hora de reunir en su secuencia las cartas que los dos poetas intercambiaron. Esta primera entrega de las ocho que se escribieron en los tres meses finales de 1916 proporciona un buen punto de partida, pues muestra, con la cadencia regular que durante largos periodos rigió la correspondencia entre ambos, los motivos y los asuntos en los que se fundamenta de inicio.

Diego inicia la correspondencia en octubre de 1916. Acaba de cumplir los veinte años, en tanto que Larrea cuenta veintiuno. Ambos amigos han concluido sus estudios de Letras en la Universidad de Deusto, donde trabaron amistad, y emprenden trayectorias vitales que implican estudios y oposiciones en lugares distantes. Acabó, pues, la convivencia cotidiana en Bilbao y las cartas vienen a suplirla, prolongando en el papel conversaciones de palabra.

$\mathrm{Y}$ dichas conversaciones escritas versan sobre lo que cabe esperar entre dos jóvenes de esa edad: amistades y amores, por un lado, aficiones compartidas, por el otro. Las familias de ambos están llamativamente ausentes, y sólo las cartas de Diego aluden a la suya como trasfondo. Dice su primera carta que «en casa» condicionan sus proyectos de estudio, y la de 21 de diciembre se refiere a "las dulzuras del hogar», que no asoman en las de Larrea. El universo que dibujan estas misivas es, por tanto, uno de puertas afuera, de jóvenes que se buscan entre amigos, que comparten aficiones y van definiendo su vocación.

Las cartas, aunque escritas para mantener la amistad de los dos incluso en la distancia, la enmarcan en un círculo de amigos comunes en Bilbao a los que mencionan repetidamente. Los Emilio Pérez Carranza, Agustín Temiño, José Valdivielso, entre otros, aparecen como fuente o destinatarios de saludos o comentarios, con lo que, en cierto modo, el epistolario reproduce o simula cierto aire de cuadrilla de amigos. Las bromas verbales que abundan en estas primeras cartas parecen propias de ese ambiente de camaradería juvenil, tanto o más que de la afición de los dos amigos a la invención verbal, que nutriría su creación de inmediato.

Sin embargo, la índole misma del intercambio epistolar, que establece entre los dos un vínculo privado, tiende a privilegiar la amistad entre los dos

1. Juan Larrea, Cartas a Gerardo Diego (1916-1980), (edición de Enrique Cordero de Ciria y Juan Manuel Díaz de Guereñu, San Sebastián, Universidad de Deusto, 1986) recogió doscientas trece cartas. Miguel Nieto recogió tres cartas de Larrea y una de Diego, fechadas entre 1965 y 1967 en "Cartas inéditas de Juan Larrea y Gerardo Diego", Contemporáneos, n 11, Jerez de la Frontera, 1992, pp. 3-10. José Luis Bernal y Juan Manuel Díaz de Guereñu, «Desteñidas esquelas. Charlas líricas. Algunas cartas de Gerardo Diego a Juan Larrea» (Ínsula, no 586, Madrid, octubre de 1995, pp. 13-16) recogió seis cartas de Diego, datadas entre 1922 y 1948. 
corresponsales, frente a la cuadrilla más amplia. Al poco, las confidencias cruzadas en asuntos de amores, así como el intercambio de noticias sobre proyectos literarios y de poemas, van configurando un ámbito de relación preferente entre los dos, sobre el que se va a fundar una larga camaradería. Esta impulsará las respectivas escrituras durante un periodo de aprendizaje determinante, en el que cristalizan ambas personalidades poéticas. Las primeras cartas del epistolario, las que publicamos aquí, ofrecen los primeros esbozos, las primeras tentativas aún titubeantes de los dos amigos por definirse como creadores.

En los dos terrenos mencionados, en el amoroso y en el poético, Larrea ejerce de mayor, un papel que Diego no titubeará en reconocerle reiteradamente al recordar estos años de búsqueda y maduración. Tal papel deriva menos de sus edades respectivas -Larrea era ańo y medio mayor que su amigo- que de sus personalidades. Donde, pese a la ligereza informal que domina las cartas, Diego se reconoce tímido, torpe o incapaz de entender, Larrea se afirma enterado, conocedor de situaciones y sentimientos, habilitado para interpretar conductas y orientar, para aconsejar y sugerir enmiendas en los poemas. Estas dos imágenes de sí mismos, que dan lugar a actitudes muy diversas pero que resultaron compatibles y quizá hasta complementarias en la relación, se habían de confirmar con los años, y el epistolario es buena prueba de ello.

En el terreno amoroso, las cartas muestran que ambos amigos comparten la propensión a la confidencia, aunque sus relatos se contraponen claramente. Larrea, en su carta de 26 de octubre, es el dominador que corta una relación, aunque no sin remordimientos o vergüenza íntima, mientras que Diego, en la suya de 23 de noviembre, es el abandonado. En dicha carta, el santanderino ofrece una versión inmediata del final del noviazgo que había de dar como fruto su primer poemario, El romancero de la novia, impreso ya en 1920. Él mismo ha recordado luego más de una vez el episodio y las circunstancias que detalla en la carta, por cuanto motivaron la composición de esa obra primeriza ${ }^{2}$.

Los tanteos iniciales de las vocaciones poéticas de Diego y Larrea son también un ingrediente fundamental en estas primeras cartas. El estilo de las misivas, que abundan en citas, alusiones y parodias, y que incurren por momentos en cierto engolamiento, deja patente el sentimiento compartido por los dos jóvenes amigos de pertenecer a una minoría selecta, capaz de apreciar en su valor las creaciones artísticas y deseosa de contribuir al acervo con las suyas propias. Entre bromas y veras, los jóvenes Larrea y Diego quizá no se consideren aún escritores, pero adoptan las posturas que entienden propias de quienes se proponen serlo.

Las cartas revelan que, en un principio, ambos entretuvieron proyectos dramáticos. Benavente es, a todas luces, autor que merece la más alta estima

2. Así, por ejemplo, en su nota de 1984 a la carta de Larrea de 10 de diciembre de 1916, que puede leerse más abajo. Da detalles al respecto, obviamente proporcionados por el propio poeta, Antonio Gallego Morell, Vida y poesía de Gerardo Diego, Granada, Universidad de Granada / Fundación Gerardo Diego, 2008, pp. 24-26. 
de ambos, que lo citan o glosan repetidamente. Larrea incluso cree descubrir en uno de los poemas que Diego le envía un eco impremeditado de un texto del dramaturgo. Es el autor de teatro por excelencia en las cartas; los demás que Diego menciona son, con ironía, «una delicia» en perspectiva; en suma, muy poca cosa. Abundan, eso sí, las alusiones a actores o actrices de renombre, a obras o salas de Madrid o de Bilbao, que expresan, por su abundancia, una afición dominante.

El intercambio de poemas parece resultado, más que de una preferencia definida por escribirlos, del hecho cierto de que las piezas son de ejecución más fácil y rápida que los dramas de ambos jóvenes autores, cuya escritura, a juzgar por las alusiones en las cartas, nunca pasa del primer acto, si es que llega a completar éste. Sea como fuere, los poemas acompañan a varias cartas desde que, en una datada en noviembre, Larrea comenta elogiosamente unas composiciones de Diego que ha conocido gracias a un amigo común -«No creí fuesen como son», concluye-, le endosa una ristra de recomendaciones y le envía un soneto.

Las composiciones de los dos amigos en estas fechas que conocemos por sus cartas no agrandarán en absoluto su prestigio literario. Nacen lastradas por las convenciones propias de aquellos días y por las que suelen acompañar a su edad de entonces. Tiene razón Larrea cuando en su carta del 10 de diciembre achaca a las de Diego ser una sombra de los autores del momento y usar las palabras consagradas, aunque lo mismo se puede decir de las suyas. Los poemas que acompañaron a las cartas pertenecen, por tanto, al ámbito de las biografías de los poetas en ciernes, más que al de sus obras propiamente dichas.

Pero dichos poemas traducen los primeros pasos creativos de unos jóvenes que aún debían probarse durante unos años antes de conseguir fruto personal y maduro. Y sirven para establecer el ámbito compartido en el que habían de desarrollar su amistad y su correspondencia. Esta no tardó en convertirse en lugar privilegiado de una reflexión común acerca de lo poético y acerca de sus expresiones posibles en aquellos finales de la segunda década del siglo.

Las ocho cartas que publicamos aquí están manuscritas, lo mismo que los poemas que las acompañaron. Transcribimos los textos según la lectura que hemos logrado. Las misivas de Juan Larrea son habitualmente legibles y ofrecen pocas dudas, aunque esta nueva transcripción corrige algún error de las precedentes. Es sabido que la letra de Gerardo Diego es, en cambio, muy difícil de descifrar. Creemos, sin embargo, haber logrado una transcripción exacta. Señalamos las pocas palabras dudosas con el signo habitual: [?].

Ofrecemos, pues, lo que creemos es transcripción fiel de las misivas, con tan sólo estas intervenciones menores que especificamos a continuación:

- corregimos los errores claros de puntuación y en el uso de las tildes, según la norma, aunque sólo en los casos que parecen obligados,

- ambos corresponsales escriben los nombres de los meses habitualmente con mayúscula; los damos en minúscula, siguiendo la norma,

- desarrollamos los números que aparecen en los originales en cifras, con la sola excepción de las fechas o las enumeraciones, 
- Larrea usa a menudo «debe» por «debe de». Corregimos los usos erróneos añadiendo la preposición entre corchetes cuando es precisa. También empleamos los corchetes para sustituir en sus cartas el inusual término "cursería» por el hoy más habitual «cursilería»,

- la anotación pretende ofrecer al lector datos y referencias que clarifiquen menciones o alusiones en las cartas, es decir, facilitar la comprensión del texto, no interpretarlo. Incluye tres notas de Diego a otras tantas cartas de Larrea, que aquel redactó en 1984 .

En dicho año tuvo lugar en la Universidad de Deusto un encuentro internacional sobre la obra de Juan Larrea. Invitado a acudir, Gerardo Diego prefirió aportar unos documentos de su archivo con destino al libro que recogió las aportaciones al encuentro. Entre dichos documentos se encontraban las cartas de Larrea datadas el 26 de octubre, el 10 de diciembre y el 30 de diciembre de 1916 y los poemas aludidos en ellas. Fue aquella la primera publicación de las mencionadas cartas, luego recogidas en un volumen con el resto de las de Larrea conservadas en el archivo Diego ${ }^{3}$. En aquella ocasión, éste acompañó los textos con unas notas explicativas que ayudan a comprender algunos pasajes de las cartas. Hemos conservado aquellas anotaciones del poeta a las tres cartas de su amigo, que distinguimos de las nuestras mediante el rótulo «Nota de Diego [1984]».

\section{Gerardo Diego y Juan Larrea: Cartas (i9i6)}

\section{GD a JL. Madrid, 25 de octubre de 1916. Manuscrita}

Madrid-25-Octubre-1916

Querido amigo Juan: mis planes de estudio de este verano fracasaron; no quisieron en casa que preparase más que una asignatura y estuve unas semanas en Bilbao dándome un ligero baño de sánscrito, en compañía de Casas. ${ }^{4}$ Pero como la cosa se presentaba aquí feílla no nos atrevimos a presentarnos. De Arqueología y Numismática no he estudiado aún nada. Quizá me presente en enero si me autorizan aunque en Secretaría me han dicho que no puede ser. Si no, lo dejaré para junio o setiembre, según el trabajo y las ganas que tenga.

Estoy abusando de tu amabilidad (y de la de Careaga). En cuanto quieras, no tienes más que avisarme para que te devuelva libros y apuntes. Con entera confianza, te diré que te agradecería que me los prestases (si no los necesitas) para cuando prepare esas asignaturas, que ya te avisaré.

3. Gerardo Diego, «Documentos», en Juan Manuel Díaz de Guereñu (Ed.), Al amor de Larrea, Valencia, Pre-Textos, 1985, pp. 275-293. Las tres cartas se integraron luego en el ya mencionado Juan Larrea, Cartas a Gerardo Diego (1916-1980), op. cit., pp. 11-12 y 15-20.

4. Las clases de sánscrito y de alemán con un profesor de Deusto fueron un truco del enamorado Diego para permanecer en Bilbao y poder visitar a su novia en el verano de 1916 (Antonio Gallego Morell, Vida y poesía de Gerardo Diego, op. cit., p. 25).

José Manuel Casas y G. Manrique y los citados más adelante en esta carta Ignacio González Careaga y Urquijo y José Valdivielso eran amigos comunes de Bilbao, los dos primeros, condiscípulos en la Universidad de Deusto. A Valdivielso alude Diego en su nota de 1984 a la carta de Larrea de 26 de octubre de 1916. 
Y tú ¿qué haces ahora?, ¿estudias algo? Por supuesto, te supongo en pleno idilio; yo he pasado algunos buenos ratos este verano.

Esto está bastante bien. En teatros no he visto nada notable. Ayer, en la corrida de la Cruz Roja, un detalle de buen gusto en la fiesta de caballeros en plaza, muy siglo XVII, resucitada con toda propiedad. Fortuna ${ }^{5}$ muy bravo.

Estamos intrigadísimos con si tendremos o no estrenos benaventinos. Hay dos en perspectiva (Comedia y Princesa) pero ninguno seguro por el estado de salud del maestro. Hace días le vimos en coche; mala traza tiene. Un día de estos iré a ver «Marianela». ${ }^{6}$ ¿Quieres algo para la Xirgú? Y esa «Puesta de sol» y esos otros proyectos y ese Pepe Valdivielso ¿en qué piensan?

Da recuerdos por ahí a los de nuestra cuerda y tú manda lo que quieras y recibe un estrecho abrazo de tu buen amigo

A tu disposición un modesto cuartito en - Tetuán-7-2º.

Gerardo

\section{JL a GD. Bilbao, 26 de octubre de 1916. Manuscrita ${ }^{7}$}

Bilbao 26 de octubre de 1916

Mi querido Gerardo: Desde que llegué a Bilbao, hará unos 15 días, estoy que si cojo o no cojo la pluma para ponerte dos letras. Enseguida me informé por Luisito Lasa del lugar en donde residías, viniendo en conocimiento de que ese lugar, pese al desprecio del nombre, era nada menos que la muy noble y nunca bien ponderada capital de Espańa; y tonto o poco menos debo [de] ser, cuando yo por mí mismo no lo he averiguado, porque ¿qué otro marco para tus futuras hazañas que no sea Madrid, iba

5. El torero Diego Mazquiarán Torrontegui, conocido en los ambientes taurinos por «Fortuna» (Sestao, 1895 - Lima, 1940). A él aluden unos versos de Diego en "Zuloaga y Machado», poema de La suerte o la muerte: "Y vendría después Diego Fortuna, / ángel de la Gran Vía» (Gerardo Diego, Obras completas. Poesía II, Madrid, Alfaguara, 1989, p. 429). Larrea pondera su valor en la carta a Diego de 2 de agosto de 1917.

6. Alude a la adaptación teatral de la novela de Benito Pérez Galdós, que realizaron los hermanos Serafín y Joaquín Álvarez Quintero. Protagonizó dicha Marianela Margarita Xirgú y se estrenó en el Teatro de la Princesa de Madrid el 18 de octubre de 1916.

7. Nota de Diego [1984]:

Pocas aclaraciones necesita esta carta, escrita tras las vacaciones al reanudarse el curso escolar, cuando-terminadas nuestras carreras- hacemos proyectos para concurrir a oposiciones. Aparecen aludidos dos amigos comunes: Luis Lasa, con otro hermano suyo del que no recuerdo el nombre, residentes en Bilbao y compañeros nuestros en Deusto, y Casas, un colombiano alumno también en la Universidad de Deusto, verdadero políglota, que pertenecía a un distinguido linaje familiar en el que se contaba ya un presidente de la República de Colombia.

De altivos pensamientos y bellos sueños es vocabulario propio de Benavente (¿̨de Los intereses creados?) al que teníamos gran respeto y leíamos con entusiasmo.

Juan nunca había sentido vocación hacia la enseñanza. Su designio era ya entonces, según consta, opositar al cuerpo de Archiveros y Bibliotecarios en el que finalmente ingresó en 1921, destinado al Archivo Histórico Nacional (a la sazón en el edificio de la Biblioteca Nacional y no donde ahora).

Al final de la carta alude Larrea con humor a su firme propósito de estudiar intensamente cuando llegue a Madrid, renunciando a otros placeres, fundamentalmente los derivados del teatro que era entonces una de nuestras pasiones. Con Benavente, de nuevo, y la Xirgú, alude a un Valdivielso que era autor de piececitas teatrales. Este tomó parte en un concurso de comedias en un acto que se celebró en Bilbao ganándolo. La obra se representó en el Círculo de los Luises que disponía de una sala de recreo para este tipo de actos y Juan había participado en algunas de las representaciones. Por cierto que a veces, como al representarse Los Galeotes de los Quinteros, un muchacho tenía que hacer los papeles femeninos. Así le ocurrió a Juan en esta ocasión. 
a ser adecuado para rodearlas y envanecerse de ellas? Porque aun el mismo Santander pongo por capital (es el único que poseo) es bien pequeño para soportar tu futura gloria. En fin, quedamos en que he sido un bellaco.

Como te decía, quince días llevo si te escribo o no, llevando hasta hoy las de ganar la pícara pereza contra todos mis buenos propósitos, cuando recibo en este momento tu agradable epístola, que hace tome una determinación enérgica y que pluma en ristre me decida a emborronar (nada más que a emborronar, por desgracia) unos pliegos de papel, que por ser para ti desearía yo fuesen pergaminos miniados por el más inspirado y pacienzudo imaginero florentino. (¡Olé ya!)

Veo que el pánico impera y que Casas y tú no parece habéis nacido para asombrar al mundo con vuestro valor. Ahora que si como dices, la cosa se presentaba feilla, no me extraña que tú, artista por instinto, amante de cosas bellas y de bellas sólo, te hayas echado para atrás. En cuyo caso y a fuer de artista por instinto también, no me resta sino decir: choca esa mano, y estrechártela con toda efusión y energía.

Mai sembla que por razones de estética y a causa del millón de gansadas que en cuanto enarbolo la pluma se me ocurren, debíais, los amigos, obligarme a cerrar el pico para evitarme meter la pata. Bien es verdad que escribo con pluma de ave (alguien diría que de ave...struz) y que son de la cola (a la que, como ves, me encuentro bastante arrimado) o del ala (y lo único que puedo hacer para agradaros es ahuecarla). ¡La virgen del Socorro me proteja! ¡Y qué charadas de gallinero me ha soplado mi desmedrada musa! ¡Perdón!, iiperdón!! ¡iiPerdón!!! (Y así sucesivamente.)

No sé si perdonarte una frasecita que como quien no dice nada me propinas en tu carta. Dícesme, después de todos tus proyectos, que, entre paréntesis, encuentro laudabilísimos: "Y tú, ¿estudias algo? Por supuesto, te supongo en pleno idilio». Pero ¿me crees capaz, querido Gerardo, de estudiar nada, sobre todo suponiéndome como con choteo me supones en pleno idilio? No estudio una palabra, y a los idilios no los conozco sino de oídas. Has de saber que todo aquel enamoramiento cursi del año pasado se fue disolviendo poco a poco en las aguas veraniegas y que llegué a Bilbao cargado de remordimientos y ayuno de altivos pensamientos y bellos sueños para desesperación de mí mismo. ${ }^{8}$ En ese estado, cogí la pluma y allí fue Troya, a la niña de mis ridículos sueños, la puse una carta de una sequedad y concisión tajantes que envolvió a sus epístolas y retratos. Ella me devolvió mis cosas con una esquelita: «Necesito hablar dos palabras contigo». Se me puso la carne de gallina. Sin embargo, accediendo a sus deseos la cité, acudí a la cita y gallardo y calavera hice maravillas que me acreditaron ante los ojos de los que están en autos, ante los saludos acarameladísimos de la niña en cuestión, y que me desacreditaron ante los míos propios. De palabra te contaré con todo detalle, pues aunque, como ingenuamente te he confesado antes, no he estudiado ni palabra, voy a tener el cinismo de presentarme en las próximas oposiciones a Archiveros, y como preparación preliminar voy a plantarme en los Madriles el próximo mes de noviembre.

Benavente, la esfinge. Para la Xirgú, na. De Puesta de sol, na, de los otros proyectos, na. De Pepe Valdivielso, na. ¡El caos!

Tendré mucho gusto en dar, como me encargas, tus recuerdos a toda esa gente. Da tú los míos a los que vaguen por ahí y hasta que personalmente pueda abrazarte, me acojo a los desacreditados e inexpresivos abrazos epistolares que, pródigo, te envía por docenas

Juan

No dejes de escribirme.

8. Como apunta Diego en su nota de 1984 a esta carta, Larrea cita un parlamento de Crispín en Los intereses creados, que encaja con el sentido de lo que escribe: «Nos despreciaríamos demasiado si no creyésemos valer más que nuestra vida...Ya sabéis quién es mi señor: el de los altivos pensamientos, el de los bellos sueños.» (Jacinto Benavente, Los intereses creados, Madrid, Cátedra, 1980, p. 78. ) 


\section{GD a JL. Madrid, 2 de noviembre de 1916. Manuscrita}

\section{Madrid-2-Noviembre-1916}

Querido amigo: con gran deleite recibí y leí tu humorística misiva y con no menos complacencia, la grata nueva de tu próxima arribada a la villa osada y madroñesca que va a tener nuevamente la honra de albergarte. O, por mejor decir, de aprisionarte, que prisiones son para los vuelos sublimes e infinitos de tu condórea inteligencia y de tu audaz fantasía, estas prosaicas mezquindades terrenas en donde el hurón hace su guarida y la raposa artera su rapińa, país de sapos, arańas y otras plagas igualmente indignas de la alteza de tu condición que nació para cernerse en aquella elevada región, allá donde el águila imperial extiende la soberanía de sus alas y complácese en mirar de hito en hito al monarca de los astros.

Pero ya que prefieres morar entre nosotros, haciéndonos la merced de acompañarnos, bienvenido seas.

Aguardo con interés tu relación de esa entrevista con que me dices ha terminado la novelita vivida. Que parece parecerse algo a la de un tu tocayo que estos días hace la delicia de horteras y horteros por estos corrales de la corte. ${ }^{9}$

Yo también me reservo el uso de la palabra para relatarte el menguado fin, a un tiempo vulgar y estupendo, de mi novela que será cursi para los demás, no para mí que puse en ella todo lo que podía poner: un corazón y un entusiasmo. Temiño ${ }^{10}$ podría contarte algo de esto, pero ya te lo diré yo si no te enoja lo tonto del suceso, que no tiene nada de romántico.

Como han pasado pocos días desde mi última carta, pocas noticias te puedo dar. Tenemos cine y Muñoz Seca en la Comedia y nos anuncian Arniches en Lara y Oliver en el Español, ¡una delicia! ${ }^{11}$ Yo pienso refugiarme en Price, en los conciertos de la Filarmónica. Hoy, si se anima Emilio (Pérez Carranza) iremos a ver «Marianela».

Recuerdos de él, de Dirao y de Lasa (Ramón). Por más que me exprimo la calabaza que tengo encima de los hombros, no consigo recordar nada que merezca la pena de contártelo; no hay más que dos soluciones: o la indiada libre o la honesta firma. Opta por la segunda tu desangelao (y desfelisao) ${ }^{12}$ amigo

Gerardo

\section{JL a GD. Bilbao, noviembre de 1916. Manuscrita}

Bilbao no sé a cuántos de noviembre

Querido Gerardo: El tiempo pasa, todo lo pausada o velocísimamente que quieras, sin dignarse dar la hora de la confección de mi maleta que hasta el día de hoy sigue tan vacía como mi cabeza. Y desesperado de esperar, y renunciando a comunicarte en esta, como era mi deseo, mi deseado viaje me decido a cumplir contigo.

Y ya que de mi viaje te he hablado te añadiré que temo no pase de la fantasía a la realidad, hasta el próximo mes de enero. No sé cuántas descabelladas ideas me sugiere traidoramente mi musa que yo, para hacerte merced, me reservo. Bástete saber que todas ellas pueden presentarse a un concurso de estupidez y curs[il]ería.

9. Alude, claro está, a la tradicional representación de El burlador de Sevilla de Zorrilla el día de difuntos, el primero de noviembre, y al mito de su personaje, don Juan Tenorio.

10. Agustín Temiño, amigo íntimo de Gerardo Diego, apodado «faquir Florestán», que reaparece a menudo en esta correspondencia hasta 1919.

11. Es decir, obras teatrales de Pedro Muñoz Seca (1879-1936), Carlos Arniches (1866-1943) y Federico Oliver (1873-1957).

12. Alusión al nombre de quien había sido su novia. Véase la carta de Diego de 23 de noviembre de 1916. 
Con paciente impaciencia aguardo el relato de tus calamidades amorosas, y a fe que te creía sumido en el quinto limbo de los enamorados, en linda plática con el rapaz amable y sinvergonzón. Y he aquí que la odiosa vulgaridad te ha hecho dar con tus huesos en el implacable prosaísmo y trocar tus amenas charlas con el rapaz antedicho, por las no tan amenas de la patrona, o de sus hijos, o sus nietos, que no son precisamente lo mismo.

Y, créeme, lo he sentido de veras. Todos esos despotismos de la vida me irritan y me duelen de tal manera que hasta llego a figurarme van contra mí.

No te extrañe pues que las espere impaciente, y que no crea en la vulgaridad y curs[il]ería que tú les achacas. Opino que en achaques en los que juega el corazón, no tienen razón de ser dichos epítetos. Podrán no ser nuevos pero nunca vulgares ni cursis, para el que pueda sentirlos.

Tuvo Temiño la buena idea de darme a leer unas poesías tuyas que saboreé con verdadero deleite. Al devolvérselas le anticipé un pequeño juicio que supongo te habrá transmitido pero que, por si acaso, volveré a repetirlo. La que más me gusta es la llamada Meditación, no por ser la más perfecta sino por ser la que revela más. Tienes frases, versos, verdaderamente inspirados. Aquella frase que termina (poco más o menos) ni una estrella - en el cielo es admirable. Sin embargo al lado de esta y otras positivas bellezas se advierten versos menos inspirados, otros vulgares y es que ¡hasta para ser poeta activo se necesita aprendizaje! ¡Lo mismo que para hacer zapatos! ¡Protestemos de esta nueva tiranía de la naturaleza!

Por lo que me han dicho tus poesías te aseguro y profetizo que si sigues escribiendo, como encarecidamente te aconsejo, llegarás a hacerlo estupendamente. Y por si algo te valen te daré unos cuantos consejos técnicos (de los otros me los puedes tú dar) que celebraré te sirvan de algo. $1^{\circ}$ ) No escojas estrofas tan difíciles como la de Meditación y los sonetos. Empieza por lo sencillo hasta que llegues a domesticar la rima, que entonces podrás hacer cuantas filigranas y florituras te vengan en gana. $2^{\circ}$ ) Nunca te dejes llevar de la rima. Es decir, que nunca cambies una idea, por otra que te pida la rima, antes de convencerte de que esta última es tan buena como la primera. $3^{\circ}$ ) No escribas deprisa sino reposadamente. Esto te hará avanzar más en menos tiempo. 4o) No busques dificultades como lo has hecho hasta ahora y $5^{\circ}$ ) escribe constantemente, y mándame de cuando en cuando tus poesías que yo sinceramente te expondré mi opinión con todo detalle, verso por verso. Y nada más sino felicitarte efusivamente por tus magníficos comienzos. No creí fuesen como son.

Te envío un soneto que hice hace un par de días para que te animes a enviarme los retoños de tu ingenio.

En Bilbao reina la monotonía más desesperante. Yo me he recluido voluntariamente en mi cuartito de trabajo, que ya conoces, donde dejo pasar las horas tranquilamente. Leo, escribo (aunque más me valiera no escribir para hacerlo tan desatinadamente) y me aburro de lo lindo. He aquí en lo que he venido a parar.

En los Campos, género chico mezclado con «El rey que rabió», «El anillo de hierro» y otras antigüedades prerromanas. ${ }^{13}$ En Gayarre, la Raquel Meller, en Olimpia y Trueba cine a todo pasto, y en el Vizcaya pantorrillas y más pantorrillas. Y por encima de todo un viento huracanado que ha derribado dos trozos de balaustrada y un farol del puente del Arenal, amén de unos centenares de paraguas, y que ha convertido a la invicta villa, al escudrińar indiscreto bajo las faldas del bello sexo, en un enorme escenario de varietés.

13. El rey que rabió, zarzuela cómica en tres actos, con música de Ruperto Chapí sobre libreto de Miguel Ramos Carrión y Vital Aza, estrenada en 1891. El anillo de hierro es un drama lírico en tres actos con música de Pedro Miguel Marqués sobre texto de Marcos Zapata, que se estrenó en 1878 . 
Bostezos, hastío, tedio y no sé cuántos proyectos fantásticos y esperanzas locas constituyen la vida (si merece este nombre) de tu mejor amigo.

Yo clavé mis ojos en lo por venir

Juan Y una voz oculta me dijo: -Serás...

Cerré yo mis ojos, no quise ver más,

Cerré mis oídos y no quise oír.

Voló mi esperanza que dio en perseguir

Lo que en este mundo no ha de ser jamás;

Y el corazón dentro, con triste compás;

-Has de ser... me dijo y rompió a reír.

Y hoy que sepultada mi esperanza fue,

Sabiendo que en polvo me convertiré

Vuelvo atrás los ojos con sed de dolor.

Soy un pobre diablo lleno de inquietud

Que ha vivido esclavo de una esclavitud.

¡He sido un iluso que murió de Amor!

Juan Larrea

Bilbao, noviembre de $1916^{14}$

\section{GD a JL. Madrid, 23 de noviembre de 1916. Manuscrita}

\section{Madrid-23-Nov[iembre]- [1]916}

Mi querido amigo: no quiero que permanezcas largo tiempo con esa paciente impaciencia del relato de mis cuitas. De sobra sabía que había de hallar en ti el interés y la discreción bastantes a que con entera confianza pueda descubrirte los escasos pliegues de mi corazón y referirte los capítulos hasta ahora vividos de mi pobre novela, aunque con toda la ignorancia y parcialidad de quien ocupa en ella tan importante puesto. Voy a procurar sintetizar porque no quiero que pierdas tú el tiempo, ni yo la tinta. Y va de cuentos...

En el verano de 1914 empecé yo a sentir eso que hemos dado en llamar «amor de amar» y que tú conoces de sobra por experiencia. Vine a Bilbao por octubre y mi iniciación en las lenguas semíticas corrió pareja con esta otra, no por más seductora menos dificultosa. Como es natural tenía yo por entonces varias candidatas, digámoslo así, aunque ninguna llegaba a convencerme lo suficiente; entre ellas figuraba la heroína de mi historia y no ciertamente en los primeros lugares.

Allá por febrero y marzo empezó la cosa a cambiar de aspecto y con tales caracteres por ambas partes que a pesar de mi hiperbólica cortedad tuve un día (21 de marzo) la estupenda audacia de aproximarme en el paseo a la recatada y, según informes, inexpugnable $\mathrm{St}^{\mathrm{a}}$. Felisa Luisa [?] que, a la sazón, se hallaba con varias de sus amigas. Como era de esperar dada mi timidez y las circunstancias de mi autopresentación, la conversación fue insulsísima. Al día siguiente en los claustros de Deusto comentábamos tú, yo y algún otro el principio de la primavera, ¿no era la fecha simbólica?

Por una serie de obstáculos, algunos imaginados y los más reales, apenas volví a hablar con ella hasta que a fines de mayo se presentó la propicia y deseada ocasión y el pórtico de Santiago fue testigo de ciertas frases cuya fe e ingenuidad asombrarían en este menguado (como todos, por supuesto) siglo de escepticismo desolador. El idilio duró poco, yo me fui a Salamanca y luego a Santander con la alegría de haber vivido las horas más felices de mi vida.

14. Poema no recogido en Versión celeste. Publicado en Juan Manuel Díaz de Guereñu (Ed.), Al amor de Larrea, op. cit., pp. 286-7, a partir del original conservado por Diego con esta carta. Recogido en Juan Larrea, Cartas a Gerardo Diego. 1916-1980, op. cit., pp. 14-15. 
Durante el pasado curso empecé a comprender que lo que yo me figuraba tan sencillo, no lo era tanto para ella. Cuanto más la conocía, menos la conocía y podrás juzgar de lo extraño de mi situación si te digo que en todo el invierno apenas llegaría a cuatro o cinco horas lo que hablamos. Pasamos por las más varias vicisitudes en la mayoría de las cuales yo no sabía a qué atenerme. En marzo se fue ella a su casa de Villaro ${ }^{15}$ y allí me fui yo a pasar una tarde y me despedí para ir a Madrid. Yo estaba entonces seguro de ella. Volví a Bilbao en junio; se reanudaron los pasados coloquios, casi todos en circunstancias alarmantes pues ya creo que te dije que el Tetrarca de Jerusalén al lado de su señor hermano era un infeliz; hay detalles de folletín que te contaría si fuese tan cómodo escribir como hablar. Volví a Santander; regresé a Bilbao por fiestas; ella estaba en Villaro. Yo la hice varias visitas en las que disfrutamos de encantadora libertad unas veces, de novelescos obstáculos otras; presentome oficialmente a sus hermanas; empezó el pueblo a rumorear. Yo estaba en el mejor de los mundos; empezaba a explicarme sus pasadas rarezas y cuando me despedí para venir aquí, estaba más confiado y seguro que nunca.

Y eso que yo siempre tuve el temor de que todo fuese un sueño en el que hubiese puesto más de imaginación que de corazón. Pronto iba a salir de dudas. A primeros de octubre recibo una carta suya en la que me anunciaba que después de meditarlo mucho se decidía a olvidarme, costase lo que costase. Para ello ponía el pretexto de las dificultades para vernos en tan largas ausencias. Como en nuestra última entrevista me había dicho todo lo contrario podrás figurarte la impresión que me produjo. Como no lo podía creer, terminé por achacarlo a cobardía suya, a miedo, a... una de sus rarezas. Insistí repetidas veces en mis promesas; por fin recibí una carta suya cuya frialdad te causaría espanto. Por acceder en todo a sus deseos se la devolví en compañía de las restantes sin una queja, sin un reproche. ¿Para qué si ellas mismas eran el mejor comentario? El final se adivina ¿verdad?; ella me devolvió las mías y en paz. Pues no señor. En el día de hoy (han pasado más de 20 días) aún nada he recibido. He vuelto a escribir reclamando y nada. Es fácil que esta última carta no la haya recibido por estar ya en Bilbao. Si un día de estos tengo tiempo y humor pondré a estas cosas tan raras un comentario psicológico, que bien se lo merece.

Y ahora cuatro palabras de «re literariae». Tu soneto me parece muy original de idea; sobrio y afortunado, quizá demasiado sincero de forma; creo que me gustaría más endecasílabo o alejandrino; esos dodecasílabos agudos para soneto suenan en mi oído con cierta monotonía. Te agradezco sinceramente tus consejos [nota a pie de página: $\mathrm{Y}$ me ruborizo ligeramente con tus alabanzas que espero no tendrán nada de aduladoras.] que seguiré... si es que continúo en mis escarceos poéticos, que lo dudo. Cumpliendo uno de ellos te envío esas dos muestras para que me las juzgues con catoniana rigidez. ${ }^{16}$

15. Hoy Areatza, villa interior de Vizcaya, cercana a Bilbao, en el antiguo camino hacia Vitoria.

16. Acompañan a la carta dos poemas manuscritos: «Soneto» y «Noviembre». Publicados en Juan Manuel Díaz de Guereñu (Ed.), Al amor de Larrea, op. cit., pp. 287-8, y recogidos en apéndice en Juan Larrea, Cartas a Gerardo Diego. 1916-1980, op. cit., pp. 427 y 430, respectivamente. Como afirma Diego en su nota de 1984 a la carta de Larrea de 10 de diciembre de 1916, no figuran en ninguna de las colecciones de poemas tempranos que Diego fue editando: Evasión, Cometa errante, Hojas. Estos dos poemas pertenecen a esa etapa primeriza en la que el poeta, según recuerda, aún no escribe poemas sistemáticamente: «Antes, desde 1915, tan sólo algunas intentonas, más para desahogar sentimientos amorosos que otra cosa» (Gerardo Diego, Versos escogidos, Madrid, Gredos, 1970, p. 11). De 1915 recoge en Cometa errante su «Soneto en Pe», por la presencia de esta consonante en todas las rimas; y de 1916 su «Soneto en qu», por lo mismo. La primera sección de Hojas está datada entre 1915-1918, y tras los dos sonetos anticipados en Cometa errante incluye el soneto "A la amistad", fechado en octubre de 1916 y el poema «La voz del corazón», fechado en noviembre de 1916, cuyo ambiente nos recuerdan 
El soneto está hecho a base de otro que hice en el verano con destino a las manos (la dulce mano que acaricia y mata ${ }^{17}$ ) que puedes suponerte aprovechando la idea y algunos versos; creo que es lo único que me ha dejado satisfecho hasta ahora. Envíame tú también algo tuyo.

Tengo que comunicarte que dentro de quince días pienso hallarme ya en Badajoz donde pasaré estas vacaciones (Montesinos -5 y 7 ). Yo también tengo mis proyectos fantásticos y los llamo fantásticos porque el que no tiene fuerza de voluntad para estudiar (con esto de las huelgas estamos al pelo) no puede tenerla para terminar una comedia aunque la tenga planeada y haya empezado a emborronar cuartillas (muy pocas). Quiero hacerme la ilusión de que me va a salir muy bien por ver si me animo a realizarla; pero creo que podrá en mí más la triste realidad de mis ensayos.

He visto a la Xirgú, Borrás y la Bárcena en «Marianela», "El Cardenal» $\mathrm{y}$ "Amanecer» respectivamente; están estupendos. ${ }^{18}$ Las obras quizá las conozcas y por eso nada te digo. Además podrás verlas cuando vengas.

Esperando los rigores de tu fallo y los nuevos que creas conveniente participarme se queda tu buen amigo

Gerardo

Si acaso vieras a Temiño recuérdale que la pereza es uno de los siete pecados capitales.

\section{SONETO $^{19}$}

Desperté de mi sueño; ¡ay!, sólo era calenturienta fiebre aquella gloria, toda aquella grandeza era ilusoria, fantasía, metáfora, quimera...

Yo pensaba: si fuese verdadera la visión de mi sueño... mi memoria perpetuada en las páginas de Historia... ¡Ay, sí! ¡Quién fuera rey! ¡Oh! ¡Quién lo fuera!

Mas no; no quiero serlo, que eso es poco

y a intentar alcanzarlo fuera loco.

En el cielo de un alma hallé un tesoro

estos textos.

17. De nuevo, cita de Los intereses creados de Benavente, donde Crispín cita este como primer verso de un soneto (Los intereses creados, op. cit., p. 67).

18. Enrique Borrás y Oriol (1863-1957), uno de los más célebres actores españoles de la época, con múltiples registros y memorables interpretaciones de clásicos y modernos. Su compañía representó las versiones en castellano y en catalán de El cardenal de Louis N. Parker.

Catalina Bárcena, actriz espańola nacida en Cuba (1896-1977). Fue una de las grandes intérpretes del teatro moderno ( $\mathrm{cfr}$. el conocido cartel de Penagos que la representa) y protagonista de Amanecer (1915) de Gregorio Martínez Sierra, a que alude Diego.

19. La versión publicada de este «Soneto» en Al amor de Larrea, op. cit., p. 287, llevó el título «[Ingenuo]» que le da Diego en su nota de 1984 a la siguiente carta de Larrea, de 10 de diciembre de 1916. Dicha versión, la que entregó Diego en 1984, mecanografiada y con correcciones manuscritas en tinta verde, presenta, además del cambio de título y de retoques en la puntuación, variantes significativas con respecto a la versión manuscrita original que acompañó a su carta, huellas de una revisión a la luz de los comentarios de Larrea en la mencionada carta: v. 4: «fantasía, farándula, quimera..." por «metáfora», siguiendo el consejo de Larrea; v. 7: «perpetuada en los bronces de la Historia» (es corrección manuscrita de «los blasones de la Historia»), igualmente por consejo de Larrea; cambia asimismo la asonancia de los tercetos que le critica Larrea: «Mas no; no quiero serlo. Otra corona / mi codicioso espiritu ambiciona» (vv. 9-10); igualmente modifica el último verso, atendiendo al consejo de Larrea: «Sólo tu reino, oh dulce amor, imploro». 
de oro y cristal, labrado en fino encaje.

¡Que un corazón me rinda vasallaje!

¡Oh, dulce amor, sólo tu reino imploro!

Gerardo Diego

Madrid - noviemb[re] - [1]916

\section{Noviembre $^{20}$}

Sobre la tristeza suprema

del mes brumario y funerario

tejer quisiera de un poema

el frío y pálido sudario.

$\mathrm{Y}$ que mis rimas trascendiesen

a los aromas cadavéricos

y que mis versos floreciesen

y fosforeciesen quiméricos

con el medroso resplandor

de un grave cirio funeral

o en el histérico temblor

de un fuego fatuo sepulcral.

Y que al leerlos se sintiera

sorda y obsesionante zumba,

algo así como si se oyera

rumor de ayes de ultratumba;

y hasta el triste suplicatorio

con que las ánimas en pena

por librarse del purgatorio

conturban nuestra paz serena.

$\mathrm{Y}$, en sueños, una pesadilla:

brujas, murciélagos, lechuzas,

en espeluznante traílla;

y grotescas escaramuzas

de fantasmas con luengas tocas

negros, rojos, hambrientos, pálidos

horrendas las desiertas bocas,

atroces los rostros escuálidos...

$Y$ es que en las horas temerosas

del mes brumario y funerario

se observa que todas las cosas

cobran tinte patibulario;

desde la campana mortuoria

que jamás es tan elegíaca,

hasta del sol la lumbre y gloria

que se nos antoja algo opaca.

Y nuestro corazón presiente

con un presentimiento vago

mientras el jardín decadente

ofrenda sus rosas al lago.

Bajo la amenaza del cielo,

20. La versión publicada en $A$ l amor de Larrea distribuye el texto uniformemente en estrofas de cuatro versos y presenta, además de retoques en la puntuación, estas variantes: v. 5: «Y que mis rimas trascendieran»; v. 13: «Y que al leerlos se sintiese»; v. 15: «algo así como si se oyese»; vv. 17-20 cambian de lugar y pasan a ser los vv. 25-28; v. 29: «Porque en las horas temerosas». 
un cielo trágico y sombrío, tendieron los cuervos su vuelo... y en mi corazón sentí frío.

Madrid - Noviembre - [1]916

Gerardo Diego

\section{JL a GD. Bilbao, 10 de diciembre de 1916. Manuscrita. ${ }^{21}$}

\section{Bilbao 10 de diciembre de 1916}

Mi querido Gerardo: ¿Tú crees que la pereza es pecado mortal? Si me respondes afirmativamente, me condenas sin remisión per in eternum. Por lo tanto ruégote te tientes la ropa antes de contestarme, y que tengas cierta benignidad en la apreciación de los pecados capitales.

Días hace estaba pensando escribirte, pero ante la duda de si continuarías en Madrid o vagarías ya por Badajoz, contuve mis buenos propósitos. Estaba persuadido de que si te escribía a Madrid no recibías mi carta por estar en Badajoz, y si te escribía a este último punto, tampoco la recibirías por continuar en la Corte. Ya sabes que la realidad, como los hombres, tiene la manía de llevar la contraria. Hasta que antes de anoche topé con Emilio Pérez quien me notificó tu estancia en la suculenta tierra de los chorizos. Ayer me pasé el día en el lecho del dolor (se empeñó en ello un insolente catarro que Dios confunda) habiéndome hoy levantado con los exclusivos objetos de oír misa, como domingo que es, y de escribirte. Cumplí con el precepto divino y me dispongo a cumplir el humano.

Has de saber, si te decides a pasar del anterior latosísimo preámbulo, que tu carta no sólo me interesó sobremanera, sino que hasta llegó a emocionarme. Haces la relación de tu desdichada historia amorosa con una tan encantadora sinceridad y tan afortunadamente que has llegado por completo a apoderarte de mi sensibilidad y me has hecho sentir tus calamidades con tal realismo como si fuesen mías.

\section{Nota de Diego [1984]:}

Dirigida a Badajoz, donde residía mi hermano Marcelino y adonde fui a pasar las vacaciones de Navidad tras completar mis estudios en Salamanca. Se nombra a Emilio Pérez (Carranza), otro de los amigos de Deusto, a él está dedicado mi libro Alondra de Verdad conjuntamente con Agustín Temiño, a quien también conocimos en Bilbao, muy aficionado a la literatura pero no estudiante en Deusto. A Emilio Pérez Carranza yo le había conocido ya en Santander, donde había estado destinado su padre con cargo de Inspector de primera enseñanza, y volví a encontrarlo, con gran sorpresa para los dos, en la Universidad de Deusto. En 1916 estaba en Madrid preparando oposiciones a cátedra de Matemáticas.

Noviazgo. Todas las alusiones, en esta carta y en la siguiente, a mi noviazgo primerizo se refieren, claro está, a la novia que tuve en Bilbao, a la que va dedicado el también primero de mis libros impreso, El Romancero de la Novia. Estando yo en Madrid el día de mi santo, el 3 de octubre, me llegó una carta suya, que yo esperaba de felicitación y abrí con mucha ilusión, en la que me comunicaba la ruptura. De ahí que Juan Larrea busque en su carta explicaciones para lo que él mismo reconoce inexplicable. Efectivamente hubo intentos de arreglo. Pero ya Juan preveía que iban a resultar infructuosos y que ella ya no significaría para mí lo mismo.

Hace la crítica de dos poemas míos, enviados sin duda por mí en la respuesta a la carta anterior. El «soneto» al que alude - diciendo que le gusta- se titula «Ingenuo». También yo pienso, ahora, que los dos poemas son, en efecto, ingenuos... y malos. Hasta ahora han permanecido inéditos y tampoco he juzgado oportuno incorporarlos a la edición de mi Poesía Completa que prepara Plaza y Janés. Los doy ahora a título de curiosidad y por referirse a ellos Larrea, junto con los tres que él me envió (no dos como la carta dice), no mejores que los míos y afectados de los mismos defectos que en los míos señala. Especialmente en el ritmo se muestra Juan Larrea modernista, acusando la lectura atenta de todos los poetas del momento. 
No te compadezco. La compasión no reza con uno mismo y como te acabo de decir he hecho mías tus tribulaciones. Las siento, eso sí, intensamente. «Y opino que lo pasado no tiene arreglo satisfactorio. Has despertado de tu sueño de amor, del primer amor, todo inconsciencia y juventud, y seguramente, aunque luego pretendieras volver a dormirte, volver a soñar, no lograrías hallar dentro de ti mismo la juventud y la inconsciencia suficientes para recomponer el ideal quebrado. Es algo que pasó. E indudablemente, en la vida humana hay épocas que pasan para no volver. Y una de ellas, tal vez la más exquisita por carecer de reflexión y humanidad es la del amor primero; vuelve más tarde el amor, más impetuoso, más intenso, si quieres, que el iniciador, pero nunca tan poético, tan sutil, tan delicado, tan amor, como el primero. Y la falta no está en el dios alado y travieso sino en nosotros mismos, en nuestro corazón. Ya te he dicho que una de las épocas de la vida es la del primer amor; no la de los primeros, sino la del único. El segundo, el tercero, el cuarto, cuantos quieras, serán iguales entre sí, pero nunca iguales al número uno.

Por eso te he dicho que juzgo no tiene arreglo. Pienso que la época del primero pasó para ti, y aunque más o menos artificialmente forjáraste otro nuevo con la misma mujer, te encontrarías con que ya no era el mismo amor, con que era el segundo con la imagen del primero. $\mathrm{Y}$ es lo probable que te hastiara dicha imagen roto el encanto y la ilusión.»

Perdóname. Me he metido con un tema inagotable y capaz de sugerirme reflexiones a millares, a cada cual más estúpida, por supuesto. Por lo tanto una vez que me he dado cuenta corto por lo sano, arrepintiéndome de haberte proporcionado tres páginas de tabarra. ¡Y esta sí que no tiene arreglo!

Y metiéndome con los hechos de tu relato, no doy con el porqué de la actitud de ella. Y digo que no lo hallo, porque no me conformo con un repentino desamor, ni con una coacción familiar, ni menos aún con la aparición de un rival afortunado. Quiero explicarlo por una extravagancia de carácter, por un algo que adivino, pero que no acierto a precisar, algo que sea un rasgo personal de un tipo de mujer. Pero en fin, si tú que la conoces, superficialmente por lo menos, no atinas con el porqué, ¿cómo he de atinar yo, iluso, que ni siquiera la conozco de vista?

¡A ver si para cuando recibas esta carta has dado anticipadamente un villano puntapié a mis teorías, reflexiones e ideas, todas tan trascendentales, arreglándote de nuevo con tu adorado tormento! Me suicido.

Leí y analicé tus poesías. Hallé singular contento con el soneto y me desconcerté con la fantasía novembrina. El soneto me parece muy bien, muy propio, muy simpático y nada vulgar. Una cosa hay que no me gusta en absoluto: la palabra metáfora empleada como la empleas. Pero no tiene muy fácil remedio. El que a mí se me ocurre no te lo digo, por no meterme en camisa de once varas. Y vamos con la métrica. El verso número tres del segundo cuarteto es algo más flojo: parece hecho a martillazos; poniendo el las a páginas debieras ponérselo a Historia. Es una pena que asonanten las rimas de los tercetos, y el verso final no sigue la cadencia. Creo que ganaría invirtiendo el orden «SSólo tu reino, oh dulce Amor, imploro!». Como ves estos son lunarcillos sin importancia. El soneto es un paso adelante. No así «Noviembre». En ella te has dejado llevar de tu fantasía, glosando versos e ideas de casi todos los poetas modernos, muy especialmente de Villaespesa y Carrere en cuanto al fondo y de Rueda, Rubén Darío y Valle Inclán en cuanto a la forma. Las palabras son todas las consagradas. Lo mejor de toda ella es la estrofa final, tampoco nueva, pero interpretada más personalmente, aunque el primer verso, muy bonito por cierto: «Bajo la amenaza del cielo» recuerda el prólogo de La Ciudad Alegre y Confiada. «Bajo la pesadumbre de un cielo...» ${ }^{22}$ Insisto 
en mis anteriores manifestaciones. Creo llegarás a escribir más que aceptablemente y con nada común facilidad. Y sobre todo, te aconsejo, procura buscarte a ti mismo. Ya ves que en estos juicios no hay ni un adarme de adulación, sino un juicio escueto y feroz en lo que se refiere a «Noviembre» y tan lisonjero como sincero en lo que se refiere al soneto. ¡Muy bien! No dejes de seguir enviándome tus producciones.

Me parece de perlas tu decisión de dedicarte a la dramática. ¡Choca! No te desanimes y sigue emborronando cuartillas, como tú dices. Y conste que luego de estas vacaciones, si voy, como espero, por Madrid, quiero leer un acto por lo menos. Y si sigo los consejos que te doy, te leeré yo también algo, pues tengo otro acto casi terminado.

No tengo ninguna poesía que merezca la pena. Sin embargo ahí te envío dos, las últimas que he hecho y que, como ves, no tienen valor alguno. ${ }^{23}$

Por aquí monotonía invernal. Mucha agua y mucha niebla. Género chico a todo pasto. Carencia absoluta de sensaciones y noticias. Así debe de ser el Limbo.

Nada más. Unas muy felices y productivas vacaciones te deseo. Mucha paciencia y mucha constancia. No dejes de tenerme al corriente de todo lo que te ocurra, y recibe el afecto incondicional del último de los mortales.

Te vi, blanca y triste, con ojos de artista

A la luz difusa de un sol vesperal.

Te hicieron mis sueños la protagonista

De una balada sentimental.

Te amé locamente, frenéticamente.

Te entregué el dominio de mi religión,

$\mathrm{Y}$ en un beso eterno, te ofrendé inconsciente

Mi corazón.

Y hoy solo ¡solo! con mi congoja

$\mathrm{Ni}$ aun besar puedo la sepultura

De mis ensueños locos de ayer,

Porque es su tumba tu boca roja

Que ha profanado la boca impura

De otra mujer.

Juan Larrea

13 nov. 1916

Mis quiméricos sueños han tenido

Un triste y doloroso despertar.

He querido llorar, mas no he podido.

¡Soñando me he olvidado de llorar!

Hundirme en mi recuerdo he pretendido

Que al fin es otro modo de sońar.

Mi pasado fue un sueño, y el Olvido

¡Ni siquiera me deja recordar!

Y heme aquí sin saber dónde me acoja

Mi espíritu a sanar, martirizado

Por la ley agobiante de vivir.

parte» de Los intereses creados, se había estrenado el 18 de mayo de ese 1916.

23. Poemas no recogidos en Versión celeste. Publicados en Juan Manuel Díaz de Guereñu (Ed.), Al amor de Larrea, op. cit., p. 286 a partir de los originales conservados por Diego con esta carta. Recogidos en Juan Larrea, Cartas a Gerardo Diego. 1916-1980, op. cit., p. 18. 
Que es mi ser una eterna paradoja:

Viejo soy y carezco de pasado.

Joven soy ${ }_{i} \mathrm{Y}$ no tengo porvenir!...

Juan Larrea

17 nov. 1916

\section{GD a JL. Aljucén (Badajoz), 21 de diciembre de 1916. Manuscrita.}

\section{Aljucén $^{24}$-21-12- [1]916}

Querido Juan: esta carta no debiera tener sino dos objetos, ya que mi vida encauzada en la más absoluta vulgaridad no ofrece nada digno de contar aunque te lo cuente todo.

Esos objetos son: $1^{\circ}$ darte las más cordiales y rendidas gracias por el interés y cariño (te advierto que te estoy escribiendo con la muñeca algo distendida, razón por la cual la carta, caligráficamente considerada, ha de resultar, si cabe, peor que de costumbre) con que has recibido el torpe relato de mis desventuras. Tú, que como buen dramaturgo, conoces bien la psicología del corazón, sabes, y lo aplicas, que no hay para ciertos males mejor remedio que la homeopatía. Al reumático, háblale de reúmas, al huérfano y al viudo de los seres perdidos, y a mí... de lo que me has hablado. Todos los que sufren tienen el inocente orgullo de creerse los más desgraciados, y este es quizá su único consuelo; esto es lo que Temińo y yo llamamos dilettantismo del dolor, cuya única razón está en (permíteme que te estropee un verso) que es "la vida» una eterna paradoja. ${ }^{25}$

Pero observo que no digo más que perogrulladas y tonterías. Y como esto de la autopsicología, si muy divertido para el que la hace, es intolerable para los demás, termino este capítulo diciéndote que creo que has puesto la mano en la llaga al tratar de inquirir la causa (?) de la conducta de mi ex-Dulcinea.

Temiño, que también opina por el estilo, cree que hay en todo ello un misterio que es necesario descubrir. Háyalo o no lo haya, puedo asegurarte que en su carácter hay algo, por no decir mucho de raro, cualidad que he podido comprobar en anteriores ocasiones.

El otro fin de la presente epístola es felicitarte las pascuas, deseándote una admirable digestión del turrón y del pavo que cristalice en inspirados versos y en acabadas escenas. Y que el próximo año te veamos coronado de laurel en la cumbre del Parnaso; ¡pero muchísimo cuidado con las musas! Que de los escarmentados nacen los avisados.

He pasado dos semanas en Badajoz, entregado a las dulzuras del hogar, pues la mayoría de los días no salía de casa (Wagner ${ }^{26}$ y una sobrinita que tengo de dos años pagaban el pato) y ahora me encuentro en este pueblo de la provincia bańado por las aguas del ahora hinchado y fiero Guadiana. ${ }^{27}$ Esto está a una legua de Mérida, cuyo acueducto se divisa claramente desde aquí; ${ }^{28}$ cuando haga bueno le haré una visita así

24. En una fábrica de harinas de esta localidad trabajaba Marcelino Diego (1885-1954), hermano de Gerardo, ingeniero industrial.

25. Diego contrahace el verso de Larrea "Que es mi ser una eterna paradoja», v.12 del soneto «Mis quiméricos sueńos han tenido», incluido en la carta precedente de Larrea, de 10 de diciembre de 1916.

26. En su biografía de Diego escribe Antonio Gallego Morell sobre estas navidades: «Compra entonces Los maestros cantores de Wagner, que toca en el piano de su hermano.» (Vida y poesía de Gerardo Diego, op. cit., p. 27.) A ello alude Diego en su nota de 1984 a la carta siguiente de Larrea, de 30 de diciembre de 1916.

27. Diego parece confundir el Guadiana con el río Aljucén, que desemboca en el Guadiana cerca de Mérida.

28. Se refiere al famoso y espléndido acueducto de los Milagros construido para llevar el agua desde el embalse romano de Proserpina, al sur de Aljucén, hasta la capital de la Lusitania. Aljucén 
como a las restantes maravillas arqueológicas... y de las otras que, según referencias, tienen mucho que ver. $\mathrm{Y}$ entre un pedrusco y una de estas graciosas castellanas injertas en andaluzas ¿quién duda?

También proyecto una excursión a la ciudad de San Fernando y de Belmonte, ${ }^{29}$ pero esta puede ser que se malogre.

La muñeca protesta y dejaré mi charla malgré mis deseos. ¿Cuándo te veremos por Madrid? Si ves a Emilio dile... que a ver si va a poder ser. Si buenamente le puedes dar las señas se las das; pero no es de precisión porque las cartas no se pierden. Son: Badajoz - G. [erardo] D[iego] - Fábrica de harinas- Estación de Aljucén-.

Recuerdos a Temiño, Pérez, Lasa, Toru, Sierra, Careaga, etc., etc. ${ }^{30} \mathrm{Tu}$ mejor amigo

Mi inacción literaria es absoluta.

Gerardo

\section{JL a GD. Bilbao, 30 de diciembre de 1916. Manuscrita. ${ }^{3 \mathrm{I}}$}

Bilbao, 30 de diciembre de 1916

Mi querido Gerardo: Fuera delito de lesa cortesía que, dada mi corrección, y la educación esmerada que he recibido, dando al olvido máximas y preceptos, no comenzara esta carta (la última probablemente del año 16 que está también en las últimas) felicitándote el año nuevo, el non nato 17. Antes que nuestro hermafrodita padre el tiempo sienta los dolores del parto, pido a Dios que el nuevo fruto con que nos obsequia, te sea propicio y que puedas marcarlo con piedra blanca en la lista ¡ojalá interminable! de tu vida.

Te iba a ensartar una docena de paradojas disparatadas sobre el año nuevo, cuando el sentido común me ha soplado al oído aquel consejo cervantino

"No te metas en honduras»

y ante esas palabras del Príncipe de los Ingenios me humillo reverente, terminando este capítulo de deseos y comenzando el de gracias.

Gracias por tu felicitación tan cariñosa que doblemente agradezco ya que, además de felicitarme con el espíritu, me felicitas con la muñeca (¿qué te ha pasado?). Gracias por las amables frases que me prodigas a lo largo de tu epístola y que no sé cómo agradecer por ser tan inmerecidas. Sírvame mi buena voluntad.

No me ha extrañado que tu novela continúe tal como la dejaste en la última carta, sin querer editar una segunda parte, y sin dejar traslucir el porqué misterioso. Ganas tengo de charlar de lo lindo contigo y entonces si tocamos, como tocaremos, este tema y si tienes la amabilidad de contarme detalles, procuraremos investigar en la probabilidad para hallar lo cierto. Has de saber que para estas cosas de sentimiento me doy una maña especial; tengo el instinto de un perro policía. Sin embargo, mucho me temo que esta vez me estrelle contra lo imposible. Intentaremos sin embargo.

Dichoso tú que tienes a Wagner y a una sobrina; dichoso tú que puedes admirar

dista algo más de Mérida de lo que Diego aprecia en la carta.

29. Sevilla, en la ruta de la Plata.

30. Amigos comunes en Bilbao, algunos de ellos ya citados: Agustín Temiño, Emilio Pérez Carranza, Luis Lasa y Sola, Ignacio González Careaga y Urquijo, entre ellos.

31. Nota de Diego [1984]:

Poco es lo que hay que explicar. Yo sigo en Badajoz, como se puede ver por las alusiones claras que se hacen a Mérida. Hay referencias nuevas al noviazgo roto y a la afición teatral, que a los dos se nos pasó pronto (no como espectadores, sino como autores que es de lo que aquí se trata). En Bilbao yo había podido comprar unas ediciones realmente baratas de las partituras de Wagner, otra de nuestras pasiones del momento, y las había tocado en el teatrillo del Círculo de los Luises a que antes me refería. 
los pedruscos emeritenses; dichoso tú que puedes contemplar tras un arco de triunfo destruido el arco de unas cejas admirables, tras la obscuridad de un vomitorio, la negrura de unos ojos entornados, tras la severa gracia de un acueducto, la gracia fina de una boca sonriente; tras el mármol frío la marmórea carne tibia; tras la esbeltez de una línea arquitectónica, la redonda esbeltez de una extremeńa; tras el alma quieta de las cosas, la inquietud anímica de una mujer siempre adorable. Dichoso tú que puedes proyectar una visita al Guadalquivir y a la Macarena. No tienes derecho a decir que tu vida «está encauzada en la más absoluta vulgaridad». Esta última frase en vez de ser tuya debiera ser mía.

Deploro de veras tu inacción literaria, y espero que cuando vuelvas a Madrid volverás a desempolvar la péñola. A mí, contra tus deseos, la digestión del turrón y del pavo me ha paralizado la inspiración, y aquí me tienes donde estaba cuando te escribí la última vez con un acto menos dos escenas, y pensando en las musarańas como de costumbre. Si no se malogran una vez más mis proyectos, pienso beberme en tu compañía para que no se nos seque el paladar con la conversación, un tonel de cerveza en cualquier bar madrileńo dentro de quince o veinte días. Pero mucho me temo caigan mis planes por tierra.

A Emilio no le he visto y por consiguiente no me ha sido posible darle tu encargo. Termino porque tengo mucha prisa.

Te abraza efusivamente 